\title{
Ljiljana Filipović
}

Freudov Mefisto

i bezvremenost

nesvjesnog

Psihoanaliza i njezine sudbine, ur. B. Mikulić, M. Žitko i S. Damnjanović, Zagreb: Filozofski fakultet Sveučilišta u Zagrebu, 2021, str. 93-108 EMAIL: ljifilipovic@gmail.com

HTTPS://doi.org/10.17234/9789531759656.03 


\section{SAŽETAK}

Sigmund Freud često navodi Goetheovog Mefista: "Das Beste, was du wissen kannst, darfst du den Buben doch nicht sagen" ["Tà najbolje što spoznao si ti/ To ne smiješ mladiće te da učiš”, $T$. Strozzi]. Tumačeći san kao ispunjenje želje, kada je san iskrivljuje u odbrani protiv nje, Freud otvoreno govori da se u društvenom životu može naići na iskrivljenje psihičkog čina kad se radi o dvije osobe, od kojih jedna raspolaže stanovitom moći, a druga mora o tome voditi računa. "Pristojnost koju svakog dana primjenjujem", otkriva Sigmund Freud, "predstavlja velikim dijelom jedno takvo pretvaranje: kad svoje snove tumačim za čitaoca, primoran sam na takva iskrivljenja." No, što je Freud prešutio? Što je iskrivio i u čemu je bio pristojan? Mnogi njegovi tekstovi i pisma koji se nalaze u Freudovu arhivu bit će dostupni tek u 22. stoljeću. Hoće li se time i zatvoriti krug djelovanja psihoanalize? Pokazati pravo značenje bezvremenosti nesvjesnog, otkrivanje potiskivanja i iskrivljavanje istine do koje se može jedino njezinom artikulacijom? 
Freud's Mephistopheles and the Timelessness of the Unconscious

Sigmund Freud often quotes Goethe's Mephistopheles: "The best thing you have known / You must not teach young men." ["Das Beste, was du wissen kannst, darfst du den Buben doch nicht sagen"]. While interpreting dreams as the fulfillment of a desire, when the dream distorts it in defense against it, Freud openly says that in social life one can encounter a distortion of the psychic act when it comes to two people, one of whom has a certain power and the second one has to pay attention about it. "The decency I apply every day", Freud reveals, "is largely such a pretense: when I interpret my dreams for the reader, I am forced into such distortions". But what did Freud keep quiet about? What did he twist and remained polite about? Many of his texts and letters are archived and will not be available until the 22nd century. Will this close the circle of action of psychoanalysis? And show the true meaning of the timelessness of the unconscious, the discovery of repression and the distortion of truth that can only be achieved by its articulation? 
"Ta najbolje što spoznao si ti / To ne smiješ mladiće te da učiš."

$\left[\right.$ Goethe, Faust ${ }^{01}$

Mnogi tekstovi i pisma Sigmunda Freuda, koji se nalaze u Freudovu arhivu, još nisu dostupni znanstvenicima. To uključuje oko sedamdesetpet tisuća stavki pohranjenih u United States Library of Congress koje nije dopušteno objaviti, u nekim slučajevima, i do dvadeset i drugog stoljeća.

Godine 1930. Sigmund Freud je dobio Goetheovu nagradu. Bio je teško bolestan te je njegov govor pročitala kćer Anna u Frankfurtu u četvrtak 28. kolovoza 1930. Nagrada mu je donijela priznanje čak i u domovini, iz koje je nekoliko godina potom, 1938., morao emigrirati. Radio Beč emitirao je pola sata s obreda dodjele nagrade kojem je prethodilo čitanje Goetheove Himne prirodi.

Već sutradan, u petak 29. kolovoza, Freud izvještava Maxa Eitingona: "Anna se vratila, veli da je bilo lijepo te da je time odana počast psihoanalizi." ${ }^{2}$ Ipak, Freudovo zadovoljstvo dobivenom nagradom nije ga zavaralo toliko da bi povjerovao kako ga je javnost prihvatila. Od samog početka bio je uvjeren da će to priznanje samo povećati otpor prema psihoanalizi. Uočio je izvještaje o svom lošem zdravlju koji su uslijedili nakon dodijeljene mu počasti. Ernestu Jonesu piše:

"Vjerojatno si i sam čuo ili čitao da strane novine izvještavaju o mome alarmantnom stanju. Mislim da su to posljedice Goetheove nagrade koju neprijateljsko javno mnijenje ne može prihvatiti bez znakova ozlojeđenosti. Tako me spremno ubijaju. E pa, ponekad mogu biti i u pravu." ${ }^{03}$

Jones u Freudovoj biografiji navodi da je nagrada iznosila deset tisuća maraka te je tako pokrila troškove Freudova boravka u Berlinu. Potvrđuje i njegovo mišljenje o protivljenju psihoanalizi i njegovoj ličnosti iskazano preko upozoravajućih članaka u kojima se izražavalo "žaljenje" da Freud samo što nije umro. To je, jasno, naglašava Jones, štetno djelovalo na njegovu praksu, jedini izvor prihoda od kojih je živio. ${ }^{04}$

01 J.W. Goethe (1970). Faust, str. 85 (prijevod Tito Strozzi). [Mefistofeles:

"Das Beste, was du wissen, darfst du den Buben doch nicht sagen”.]

02 The Diary of Sigmund Freud 1929-1939. A Record of the Final Decade Translated, Annotated, with an Introduction by Michael Molnar (1992).

Pismo Freud-Eitingon, 30. 8. 1930., str. 80.

03 Ibid., str. 8o-81.

04 Džons E. [Jones] (1985), Život i delo Sigmunda Frojda 2, str. 338. 
U govoru povodom Goetheove nagrade Sigmund Freud je istaknuo da je odnos prema očevima i učiteljima ambivalentan, naše divljenje prema njima redovito pokriva komponentu neprijateljske pobune. To je psihološka sudbina, ne može se promijeniti bez nasilnog potiskivanja istine. Govor završava citiranim Mefistovima riječima iz Goetheova Fausta. ${ }^{05}$

Freudu su to omiljene Goetheove riječi. Navodi ih i u pismu Wilhelmu Fließu 3. prosinca 1897. godine: "Otkad proučavam nesvjesno, postao sam tako zanimljiv samome sebi. Šteta što kod onog najintimnijeg uvijek držimo jezik za zubima." I tada ponovno navodi Goethea uz malu izmjenu: "Das Beste, was Du weißt / Darfst Du den Buben doch nicht sagen." [“Najbolje što znaš, ipak ne smiješ kazati dječacima”] ${ }^{06}$

S Mefistom se susrećemo i u Tumačenju snova iz 1900. godine gdje u sklopu razotkrivanja sna kao ispunjenja želje, kada je san iskrivljuje u odbrani protiv nje, Freud napominje da "se i u društvenom životu može naići na slično izopačenje psihičkog čina. Naime, kada se radi o dvije osobe, od kojih jedna raspolaže stanovitom moći, a druga mora o tome voditi računa”. Priznaje da pristojnost koju svakog dana primjenjuje, predstavlja velikim dijelom jedno takvo pretvaranje:

“... kad svoje snove tumačim za čitatelja, primoran sam na takva iskrivljavanja. O prisiljavanju na takvo izopačavanje žali se i pjesnik: 'Najbolje što možeš znati, ipak ne smiješ reći dječacima.”’7

U pismu Oscaru Pfisteru, svećeniku i psihoterapeutu, od 10. rujna 1918., Freud otkriva svoje stajalište o ljudskoj prirodi: "Ne razbijam previše glavu o dobru i zlu, malo sam 'dobrog' otkrio kod ljudi. Prema mome iskustvu, većina njih je smeće.”os

05 S. Freud (1982/1930). “Ansprache im Frankfurter Goethe-Haus”, str. 296.

06 S. Freud S. (1986). Briefe an Wilhelm Fließ, 1887-1904, str. 310: "Seitdem ich das Unbewußte studiere, bin ich mir selbst so interessant geworden. Schade, daß man sich fürs Intimste immer den Mund verschließt.”

07 Navod prema prijevodu Albina Vilhara, Frojd, S. (1984). Tumačenje snova I, str. 147. Freud, S. (1982/1900) "Die Traumentstellung”, Die Traumdeutung, Studienausgabe Bd. II, str. 158.

08 Sigmund Freud to Oscar Pfister: "I do not break my head very much about good and evil, but I have found little that is 'good' about human beings on the whole. In my experience most of them are trash." Navod prema Peter Bruggen/Raj Persaud (2020), "Covid-19 on the Couch: Sigmund Freud's Surprising Analysis”, Psychology Today, April 26, 2020 (https://www.psychologytoday.com/intl/blog/slightly-blighty/202004/ covid-19-the-couch-sigmund-freuds-surprising-analysis). 
Ferenczi zapisuje u dnevnik 1. svibnja 1932.:

“Sjećam se stanovitih Freudovih primjedbi koje je izrekao u mojoj prisutnosti, očito računajući na moju diskreciju: 'Pacijenti su ološ.' Vjerujem da je Freud izvorno iskreno vjerovao u analizu: oduševljeno je slijedio Breuera, strasno i odano zaokupljen pomaganjem neurotičnim pacijentima (ležeći satima na podu pored pacijenta kad je bio u histeričnoj krizi) isprva je sigurno bio potresen, no onda su ga otrijeznila stanovita iskustva u Breuerovom slučaju, recidiva pacijenata i posljedice problema protuprijenosa koji se iznenada otvorio pred Breuerom poput ponora. U Freudovu slučaju to odgovara otkriću lažljivosti histeričara. Nakon tog otkrića, bolesnici Freudu više nisu bili dragi. Vratio se voljenju svoga urednog, kulturnog Nad-ja.” ${ }^{9}$

Međutim, što je to Sigmund Freud prešutio? Prizivajući upravo opomenu Goetheova Mefista. Što je to iskrivio i pristojno zatajio vlastitoj publici? A čini se i znanstvenicima? Što je ono za što je mislio da nismo spremni saznati? Da će ljudi biti pametniji i otvoreniji prema samima sebi tek u 22. stoljeću?

Nije Sigmund Freud otklonio pristup svojim spisima. Iako je to možda i želio. Mikkel Borch-Jacobsen u knjizi The Freud Files: An Inquiry Into the History of Psychoanalysis podsjeća da je 1951. godine psihoanalitičar Kurt Eissler oduševio Annu Freud najavom o osnivanju Arhiva Sigmunda Freuda čiji bi počasni članovi bili, između ostalih, a i uz njih, i Albert Einstein i Thomas Mann. Pokazalo se da cilj nije bio da Arhiv bude otvoren za javnost nego da posluži kao sef u kojem će materijali biti pohranjeni daleko od znatiželjnika. ${ }^{10}$

Tajne je djelomično izvukao 1984. i objelodanio u svojoj knjizi The Assault on Truth Jeffrey Moussaieff Masson koji je stanovito vrijeme bio direktor Freudova Arhiva. Mišljenja je da je Freud napustio svoju teoriju zavođenja jer se plašio da bi odobravanje istine o tvrdnjama

09 Dio iz dnevnika naveden je u knjizi Jeffreya Moussaieffa Massona The Assault on Truth (1984), str. 102: "Ferenczi says: I remember certain remarks that Freud made in my presence, evidently counting on my discretion: 'Patients are riffraff.'” (iz članka Ralpha Blumenthala "Freud: secret documents reveal years of strife", https://www.nytimes. com/1984/o1/24/science/freud-secret-documents-reveal-years-of-strife. html? smid=em-share).

10 Mikkel Borch-Jacobsen (2011) The Freud Files: An Inquiry Into the History of Psychoanalysis. 
njegovih pacijentica da su bile seksualno zlostavljane ometalo prihvaćanje njegovih psihoanalitičkih metoda. ${ }^{11}$

Jeffrey M. Masson otpušten je 1981. godine s položaja direktora projekta u Arhivu Sigmunda Freuda ubrzo nakon govora u New Havenu sugerirajući, na temelju Freudovih pisama kao i drugih informacija, da je ključna Freudova teorija, razvijena 1895., takozvana teorija zavođenja (Verführungstheorie), koju je kasnije odbacio — možda ipak bila ispravna. Da se nije radilo samo o fantazijama pacijentica da su seksualno zlostavljane, nego da su emocionalni poremećaji odraslih ipak, kako je Freud u početku smatrao, nastali zbog stvarnih, kasnije potisnutih, ranih traumatskih doživljaja.

Masson je učinio dostupnim prethodno neobjavljena Freudova pisma prijatelju Wilhelmu Fließu, koja razotkrivaju da je Freud ozbiljno dvojio o napuštanju "teorije zavođenja". Masson je otkrio da Freud ne samo da je čitao tadašnju literaturu, koja je dokumentarno otkrivala veliki stupanj seksualnog zlostavljana djece, nego je, čini se, prisustvovao i autopsijama djece koja su bila silovana i ubijena. Mišljenja je da je Sigmund Freud napustio svoju teoriju zavođenja više zbog nedostatka hrabrosti nego kliničkog i teoretskog uvida.

Knjiga je uzburkala frojdističku i psihijatrijsku scenu, pa se uz brojne tekstove pojavio i dokumentaristički roman Janet Malcolm In the Freud Archives. ${ }^{12}$ Autorica se poigrala romanesknim susretom psihoanalitičara Kurta R. Eisslera, Jeffreyja M. Massona, upadljivim četrdesetdvogodišnjakom, poznavateljem sanskrta, obraćenim psihoanalitičarem, te Peterom Swalesom, tajanstvenim, nestašnim tridesetpetogodišnjim, bivšim suradnikom Rolling Stonesa i samoukim proučavateljem Freuda. Tko će naslijediti tajne Sigmunda Freuda, pitanje je koje se tragikomično poigrava trojicom likova od kojih je svaki uvjeren da zna istinu o Freudu. Ipak, zbog pisanja Janet Malcolm, Jeffrey Moussaieff Masson tražio je odštetu od deset milijuna dolara za klevetu da je izmislila njegove izjave. Nakon desetljeća procesa porota je presudila u korist autorice jer bez obzira jesu li navodi točni, zaključilo se da bi ipak bilo potrebno više dokaza da bi je se osudilo. No, gotovo skandal, svakako je pomogao promidžbi njihovih knjiga.

U veljači 2017. u United States Library of Congress, oslobođeno je dvadeset tisuća dokumenata koji su pripadali Freudu. Obiteljska pisma

11 Jeffrey Moussaieff Masson, J. M. (1984) The Assault on Truth: Freud's Suppression of the Seduction Theory.

12 Janet Malcolm (1984), In the Freud Archives. 
kao i prepiska s Carlom Jungom, Albertom Einsteinom, Thomasom Mannom i drugima, otkrivaju kontroverze u psihološkim teorijama kao i svakodnevnim problemima.

Hoće li 22. stoljeće s upoznavanjem sa sadržajem Freudovog Arhiva time i zatvoriti krug djelovanja psihoanalize? Pokazati pravo značenje bezvremenosti nesvjesnog, razotkrivanje potiskivanja i iskrivljavanje istine do koje se može jedino njezinom artikulacijom?

Ideja je Freudove teorije zavođenja, koju je razvijao u razdoblju između 1895. i 1897., a potom napustio, da je sjećanje na zbiljske prizore zavođenja jedna od glavnih odrednica etiologije neuroza. Kasnije, Freud u Autobiografiji govori o tome kao zabludi:

"Kada sam se pribrao, izvukao sam iz svog iskustva ispravne zaključke: da neurotični simptomi nisu izravno vezani za stvarne doživljaje već za želje u fantaziji i da za neurozu psihička realnost više znači od materijalne."

Time počinje i uvod u razmatranje Edipovog kompleksa, koji, kako nam Freud otkriva: "još nisam prepoznao u tako fantastičnom prerušavanju”. No, Sándor Ferenczi nastavlja 1932. s teorijom zavođenja te zaključuje da seksualnost odraslih (“jezik strasti”) izvodi istinski prepad na dječji svijet (“jezik nježnosti”). ${ }^{14}$

Za Laurenta Guyénota Massonova knjiga razotkriva mračnu stranu civilizacije i prikrivanje bez premca. Ističe Massonov navod da je Sándor Ferenczi u svom dnevniku u srpnju 1932. godine zapisao da bi "Edipov kompleks mogao biti rezultat stvarnih djela odraslih, naime nasilnih strasti usmjerenih prema djetetu, koje potom razvija fiksaciju, ali ne iz želje, kako je smatrao Freud, nego iz straha. 'Majka i otac će me ubiti ako ih ne volim i ako se ne poistovjetim s njihovim željama'”. Ferenczi je zastupao postavku da bespomoćnost uzrokuje to da žrtva suosjeća s agresorom, što je danas poznato kao "Stockholmski sindrom”. Ferenczijevo predavanje "Zbunjenost jezika” naišlo je na isto neodobravanje članova psihoanalitičkog udruženja kao i Freudova "Etiologija histerije". No, sada su Sigmund Freud i njegove pristalice izopćili Ferenczija, a njegov rad nikad nije preveden na engleski jezik za Međunarodni časopis za psihoanalizu, kao što je to bilo uobičajeno. Umro je nakon nekoliko godina kao slomljen čovjek.

13 Navod prema prijevodu Vladete Jerotića, Frojd S. (1984). Autobiografija, str 37. Freud S. (1924/2008). Selbstdarstellung.

14 J. Laplanche / J-B. Pontalis (1992). Rječnik psihoanalize, str. 507. 
Dodatni uvid, smatra Laurent Guyénot, donijele su i knjige Marie Balmary, Freud and the Hidden Fault of the Father, te Marianne Krüll, Freud and His Father. Autorice se, kao i Jeffrey Moussaieff Masson, pozivaju na Freudova pisma Fließu, pokazujući da je Freud svojom introspektivnom samoanalizom doveden do teorijskog prevrata. Balmary i Krüll ističu da je Freud poduzeo samoanalizu neposredno nakon smrti oca. Deset dana nakon očeve smrti, 2. studenog 1896., Freud je pisao Fließu o snu noć prije sprovoda, u kojem se pojavio natpis: "Od vas se traži da zatvorite oči", što je protumačio kao upućivanje na "nečiju dužnost prema mrtvima”. Ipak, 11. veljače 1897., nakon što je spomenuo da prisilni oralni seks kod djece može rezultirati neurotičnim simptomima, dodaje: "Nažalost, moj je vlastiti otac bio jedan od tih perverznjaka i odgovoran je za histeriju moga brata i nekoliko mlađih sestara." Napokon, 15. listopada, osvrnuo se na Edipovu priču:

"Sinula mi je jedna ideja opće vrijednosti. Otkrio sam, i u vlastitom slučaju, [fenomen] zaljubljenosti u majku i ljubomore prema svom ocu, i sada to smatram univerzalnim događajem u ranom djetinjstvu."15

Neugodan je podatak i da su Freudovog unuka, Sir Clementa Freuda, britanskog parlamentarnog zastupnika, nakon smrti, njegove žrtve optužile za pedofiliju i silovanje. Njegova se supruga oglasila na te optužbe, javno izrazivši žaljenje zbog toga što im se dogodilo, nadajući se da će im time omogućiti mir. ${ }^{16}$

Freudova nesklonost da otkrije svoja saznanja, nalazeći podršku u manipulacijama ipak jednog demona, otkriva i njegovu podvojenost $i$ mogućnost da unatoč namjernom potiskivanju ono izmakne kontroli. Pa tako i proigra cilj za autentičnom promjenom čovjekovih stajališta.

Shakespeare se nije zamarao teorijom potiskivanja. Dojadilo mu je u njegovom 17. stoljeću ulagivati se publici da ga ne bi napustila. Nije mu se još pet stoljeća podržavalo laži malograđanštine. Djecu se zlostavlja! Nije to nešto što se smije pragmatično prikrivati. Da ne bi

15 Laurent Guyénot (2019), Freud, Sexual Abuse, and B'nai B'rith, The UNZ Review, September 30, 2019 (https://www.unz.com/article/freud-sexualabuse-and-cover-up/).

16 The Guardian, 14 June 2016 (https://www.theguardian.com/uknews $/ 2016 /$ jun $/ 14 /$ sir-clement-freud-accused-of-abusing-two-girlsbetween-the-late-1940s-and-7os). 
bilo zabune, na samom početku djela Periklo, dolazi uvodničar Gower, kao kor, i otkriva što se događa na Antiohovu dvoru:

"Kći ta bje vedra, divna, blaga,

Ko da bje samom nebu draga.

Otac je ljubit poče vruće

Počinivši rodoskvrnuće:

Loša kći, gori otac, što je skloni

$\mathrm{Na}$ takav grijeh, kog svatko nek se kloni.

$\mathrm{Al} s$ vremenom to grešno djelo

Navika duga zbrisa cijelo." ${ }^{17}$

Hoće li se, nakon stoljeća Freudove psihoanalize, kada se iščeprkaju sve tajne, zabune, svađe i prijetvornosti, moći govoriti o razotkrivenoj psihoanalizi? Kad sadašnjost bane u prošlost, kao da se radi o potrazi za izgubljenim vremenom, pretvarajući je u budućnost? To što je učinio odbor koji je zatočio Freudove rukopise, intervencija je u vremenu.

Jacques Rancière ukazuje da "pripovijest o vremenu uvijek definira ono što je sada prisutno, način na koji se to prisutno pridružuje nekoj prošlosti ili se od nje razdvaja, što omogućuje ili zabranjuje budućnost. Međutim, osobito je značajno da je pripovijest o vremenu uvijek istodobno fikcija o vremenskoj pravdi."18 Taj izraz "vremenska pravda" podsjeća, veli Rancière, "na Anaksimandrovu rečenicu o načinu na koje se stvari podvrgavaju plaćanju za njihovu nepravdu u vremenskom poretku (...) Velika pripovijest o vremenskoj pravdi svodi se dakle na jednostavnu opreku između vremena onih koji znaju i vremena onih koji ne znaju."

Riječima Marca Augéa, povijest se ubrzava. Odlučili ste i sami uplesti se u izricanje mišljenja o vremenu. Gadno! Već su svi nešto rekli. A vi možete samo govoriti o prolaženju vremena promatrajući ruke kojima pišete. Jedva zađemo u godine, a prošlost nam je već postala povijest i naša

17 William Shakespeare (1987). Periklo, Zagreb: Nakladni zavod Matice hrvatske, str. 46, prijevod L. Paljetak. [Shakespeare, W. (1968) Pericles, Prince of Tyre, New York: Washington Square Press, str. 2 "This king unto him took a peer, / Who died and left a female heir, / So buxom, blithe and full of face / As Heaven had lent her all His grace, / With whom the father liking took / And her to incest did provoke, / Bad child, worse father! To entice his own / To evil should be done by none. / But custom what they did begin / Was with long use accounted no sin."]

18 Jacques Rancière (2015). Politike vremena, "Vrijeme, pripovijest i politika", sveska br. 6, str. 21 i dalje. (Prijevod: Edicija Jugoslavija.) 
osobna povijest već pripada Povijesti. ${ }^{19}$ Marcel Proust je već sve izrekao:

"A možda me je San opčinio i time što se tako strašno igra s Vremenom. Zar nisam često vidio u jednoj noći, veoma davna vremena, prognana u one goleme daljine u kojima ne možemo više ništa raspoznati od osjećaja koji su nas ovdje obuzimali, kako svom snagom nasrću na nas zasljepljujući nas svojom svjetlošću, kao da su divovski avioni mjesto blijedih zvijezda, kao što smo mislili, kako nam pokazuju sve ono što su za nas sadržavali, uzbuđujući nas, potresajući nas, obasjavajući nas svojim neposrednim susjedstvom - a koja su se ponovno vratila, kad smo se probudili, u onu daljinu koju su nekim čudom prešla, dok nas nisu uvjerila, uostalom sasvim krivo, da su jedan od načina kako da ponovno nađemo 'izgubljeno vrijeme."'

Dobar dio Pronađenog vremena, posljednje knjige, napisan je istodobno kad i Put $k$ Swannu, no prerađen je i proširen prije objavljivanja. Premda je Marcel Proust bio Freudov suvremenik, i unatoč podudarnostima u razmišljanju, nisu se međusobno čitali.

Može li se onda govoriti kako je kraj poznat, iako je tek početak? To da se vrijeme, nesvjesno, obraća iz budućnosti? Da se izgubljeno vrijeme pronalazi u snu? Nije to neki misterij. Znakove ispisujemo sami. Slijedimo vlastite tragove. Ostvarujemo budućnost. Snu koji žonglira s vremenom još prije no što utonemo u njega, ili kad iz njega izranjamo, kad je sjećanje nedohvatljivo. Vlastita memorija utječe na našu percepciju ispisujući budućnost. Naknadno. ${ }^{21}$

Film je nasljeđe sna. Rancière ističe njegovu sposobnost da nekoliko vremena stavi u jedno, kontinuitet i fragmentiranje, povezivanje i ponavljanje, nasljeđe i suživot. ${ }^{22}$

Kad Marc Augé kaže, iako u drugom kontekstu, da su nemjesta, gdje su odnosi, povijest i identiteti izbrisani poput goleme zgrade, koja iz dana u dan prima sve više pojedinaca, može se tako govoriti i o ne-vremenu, svi smo stalno zajedno, a stajalište percepcije je ono kojim ponekad želimo izbjeći sami sebe. "Nemjesto je oprečno utopiji: doista

19 Marc Augé (2001). Nemjesta, Karlovac: Naklada Društva arhitekata, grad'evinara i geodeta, str. 100, str. 29 (prijevod V. Valentić).

20 Marcel Proust (1977). Pronađeno vrijeme II, str. 27 (prijevod V. Tecilazić).

21 Jacques Derrida (1987), "Frojd i scena pisanja” (prijevod A. Moralić), str. 435 .

22 Jacques Rancière (2017). Modern Times, str 140. 
postoji, a u njemu ne prebiva nikakvo organičko društvo." ${ }^{23}$ Upravo kao i nesvjesno. Nesvjesno koje ne poznaje vrijeme jest vrijeme.

Ontički, ustvrđuje Lacan, nesvjesno je neodređeno, no može ga se zaokružiti u vremensku strukturu. Opisuje nesvjesno kao ono koje se pojavljuje u vremenskoj pulsaciji, što se zatvara čim se otvorilo. Tako je nesvjesno nešto izuzetno, zatvoreno iznutra, $u$ što moramo prodrijeti izvana. ${ }^{24}$ Također, nesvjesno traži vrijeme da bi se otkrilo.

Slavoj Žižek podsjeća da strukturalističko postavljanje odsutnosti na istu razinu s prisutnošću ujedno znači postavljanje na istu razinu prošlosti i budućnosti sa sadašnjošću: "proboj metafizičkog prvenstva sadašnjosti”. Ono/Es je bez vremena utoliko što uvijek zna kako $\mathrm{mu}$ "buduće ispunjenje svrhe, buduća sadašnjost njezina prisuća, neće ispuniti sadašnji nedostatak", kako su prošlost i budućnost na istoj razini sa sadašnjošću. Slom prvenstva sadašnjeg kroz postavljanje-na-istu-razinu triju dimenzija vremena dobro je izveden, uočava Žižek, u Heideggerovu Zeit und Sein: "Prošlost kao ne-više-sadašnjost i budućnost kao još-ne-sadašnjost nisu — kao u metafizici — deficitarni modusi sadašnjeg, nego jednakoizvorne dimenzije koje su 'sve već ovdje’: prošlo je upravo prisutno na način ne-više-prisutno sadašnjeg, itd. No tragove tog prodora možemo pratiti čak do stoičke kritike Aristotelova shvaćanja vremena i sadašnjeg-momenta kao granice između budućeg i prošlog." ${ }^{25}$

Osnivači Freudovog Arhiva intervenirali su u vrijeme, u memoriju. Kad je tumačio Hamletovu dvojbu, i oklijevanje da osveti oca, Sigmund Freud je ukazao kako je došlo do civilizacijskog potiskivanja u odnosu na Kralja Edipa kad je bila sasvim uočljiva želja da oca smakne s puta. Hamlet tu želju ne prepoznaje. U slučaju zabrane pristupa Freudovoj dokumentaciji, radi se o sasvim otvorenom zastupanju memoriae negativae koja funkcionira poput tlačiteljske moći.

Hamlet podsjeća:

The time is out of joint: $\mathrm{O}$ cursed spite,

That ever I was born to set it right!

23 Marc Augé (2001). Nemjesta, str. 100.

24 J. Lacan (1964 /1973), Les quatre concepts fondementaux de la psychanalyse, str. 40.; J. Lacan (1986), Četiri temeljna pojma psihoanalize (prijevod Mirjana Vujanić-Lednicki), str. 38.

25 S. Žižek (1976). Znak/označitelj/pismo, str. 171. 
... Raskliman je svijet

Prokletstvo, što se ikad rodih mlad,

Da u taj nered opet vratim sklad. ${ }^{26}$

Ne radi se tu samo o konfuznoj političkoj situaciji, koje se vole ponavljati. Vrijeme je uvijek proigrano, rijetko se kad radi o "pravom" trenutku. Hamlet je stručnjak za odugovlačenje koje prikriva prave motive nedjelovanja.

Christian Boltanski svojom instalacijom Vanitas ističe:

“Želim da se vrijeme čuje i osjeća, Ljudi su sposobni za mnogo toga ali ne mogu preokrenuti tijek vremena. Bog je Gospodar vremena., ${ }^{27}$

U Nelagodi u kulturi iz 1930. Freud ponovno progovara preko Goetheovog Mefista ističući da veoma uvjerljivo djeluje identifikacija principa zla s nagonom razaranja:

"Ja duh sam koji vječno poriče!

I s pravom baš: jer sve što rodi se,

Zaslužuje da propadne;

Stog bolje bilo bi kad nastajalo ne bi;

I zato sve što grijeh je tebi;

Razaranje, no jednom riječi, zlo,

Element moj je zapravo." 28

Nesvjesno ne zaboravlja. Nema tu sposobnost. U njemu je sve prisutno istog trenutka. I prošlost, i sadašnjost $\mathrm{i}$ budućnost. Njegova je bezvremenost fluidna. Utisci se slažu jedni na druge. Prepliću se. Briga ih jesu li u nekom time lineu. Iskočit će kad ih se najmanje očekuje.

Da, sigurno će Freudov Arhiv otkriti pokoji skandal i izdaju prijateljstva. Pragmatičnost pogrešnog djelovanja. Ničeg tu nema novog. Najveći je debakl zataškavanje eventualne istine. Bezvremenost

26 W. Shakespeare (1994). Hamlet (izd. London: Penguin Books), str. 55. W. Shakespeare (1950) Hamlet (prijevod Milan Bogdanović) str. 65.

27 8th art project Salzburg Walk of Modern Art: Christian Boltanski, "Vanitas" (2009) in the Crypt of Salzburg Cathedral.

28 J. W. Goethe (1970), Faust (prijevod Tito Strozzi), str. 63. Usp. S. Freud, S. (1930/1982) "Das Unbehagen in der Kultur", Studienausgabe Bd. 9, str. 248. S. Freud (1984). "Nelagodnost u kulturi”, str. 328 (prijevod V. Matić, V. Jerotić, Đ. Bogićević). Film Faust F. W. Murnaua iz 1926. Richard Brody u lipnju 2014. godine proglašava filmom tjedna. (https://www. newyorker.com/culture/richard-brody/movie-of-the-week-faust) 
nesvjesnog dohvatilo je odgođeno vrijeme istine. Arnoldu Zweigu, na prijedlog da napiše njegovu biografiju, strogo je odgovorio:

"Istina nije dostupna; čovječanstvo je ne zaslužuje. I nije li kraljević Hamlet bio u pravu kad je pitao tko će ostati neišiban ako se svakome postupi prema zasluzi." ${ }^{29}$

Pisma, dnevnici i teorijske dvojbe bit će temeljem za autopsiju Freudove osobnosti. Upozorio je sâm na to u svom frankfurtskom govoru. Iznjedrio je velik poklon čovječanstvu, ali ono ga još ni sada nije sasvim sposobno prihvatiti. Kao što je poznato, Sigmund Freud je smatrao da plan stvaranja svijeta nije sadržavao namjeru da čovjeku dâ sreću: "Stvoreni smo da možemo intenzivno uživati samo u kontrastu, a u jednom stanju vrlo malo."

Nije neobično da Danteov Raj dolazi na kraju trotomnog djela. Lakše je osuditi nego nagraditi. Nije slučajno da je Goetheov Mefisto lajtmotiv Freudova razmišljanja.

29 Džons E. (1985), Život i delo Sigmunda Frojda 2 (prijevod V. Čolanović), str. 375 .

30 S. Freud (1930/1982). "Das Unbehagen in der Kultur”, str. 208; S. Freud, (1984), "Nelagodnost u kulturi”, str. 277. 


\section{B I B LIOGRAFIJA}

Augé, Marc (2001). Nemjesta. Prijevod V. Valentić Karlovac: Naklada Društva arhitekata, grad'evinara i geodeta.

Blumenthal, Ralph (1984), "Freud: secret documents reveal years of strife", https://www.nytimes.com/1984/o1/24/science/freud-secret-documentsreveal-years-of-strife.html? smid=em-share).

Boltanski, Christian (2009), "Vanitas”. 8th Art Project Salzburg Walk of Modern Art (https://www.salzburg.info/en/salzburg/creative-salzburg/ art-in-public-room/walk-of-modern-art/vanitas).

Bruggen, Peter/Raj Persaud (2020), "Covid-19 on the Couch: Sigmund Freud's Surprising Analysis”, Psychology Today, April 26, 2020 (https:// www.psychologytoday.com/intl/blog/slightly-blighty/202004/covid-19the-couch-sigmund-freuds-surprising-analysis).

Borch-Jacobsen, Mikkel and Sonu Shamdasani (2011). The Freud Files: An Inquiry Into the History of Psychoanalysis, Cambridge: Cambridge University Press.

Derrida, Jacques (1987), “Frojd i scena pisanja”, u: Filozofsko čitanje Frojda, ur. Obrad Savić, Beograd: Istraživačko-izdavački Centar SSO Srbije, 1987 (prijevod Ana Moralić).

Džons, Ernest [Jones, E.] (1985) Život i delo Sigmunda Frojda 2, Novi Sad: Matica srpska (prijevod V. Čolanović).

Freud, Sigmund (1924/2008), Selbstdarstellung, Frankfurt am Main: Fischer Taschenbuch Verlag.

Freud, Sigmund (1982/1930), "Das Unbehagen in der Kultur”, Studienausgabe Band IX, Frankfurt am Main: Fischer Taschenbuch Verlag.

Freud, Sigmund (1982/1900), Die Traumdeutung. Studienausgabe Bd. 2, Frankfurt am Main: Fischer Taschenbuch Verlag.

Freud, Sigmund (1982/1930). "Ansprache im Frankfurter Goethe-Haus”.

Studienausgabe Bd. 10, Frankfurt am Main: Fischer Taschenbuch Verlag. Freud, Sigmund (1986). Briefe an Wilhelm Fließ, 1887-1904, Frankfurt am Main: S. Fischer Verlag.

Frojd, Sigmund (1984). "Nelagodnost u kulturi”. Izabrana dela Sigmunda Frojda, Sv. 5. Novi Sad, Matica srpska (prijevod Vojin Matić, Vladeta Jerotić, Đorđe Bogićević).

Frojd, Sigmund (1984). Autobiografija, Izabrana dela Sigmunda Frojda, Sv. 8, Novi Sad: Matica srpska (prijevod Vladeta Jerotić).

Frojd, Sigmund (1984). Tumačenje snova I-II. Izabrana dela Sigmunda Frojda, Sv. 6-7, Novi Sad: Matica srpska (prijevod Albin Vilhar).

Goethe, Johann W. (1970), Faust. Prijevod Tito Strozzi, Zagreb: Zora, Matica Hrvatska. 
Guyénot, Laurent (2019), “Freud, Sexual Abuse, and B'nai B'rith”, The UNZ

Review, September 30, 2019. (https:/www.unz.com/article/freud-sexualabuse-and-cover-up/).

Lacan, Jacques (1986), Četiri temeljna pojma psihoanalize, Zagreb: Naprijed, prijevod Mirjana Vujanić-Lednicki. (J. Lacan, Le séminaire 1964. Livre XI, Les quatre concepts fondementaux de la psychanalyse, Paris: Seuil, 1973.)

Laplanche, Jean/J-B. Pontalis (1992). Rječnik psihoanalize, prijevod Rada Zdjelar i Boris Buden. Zagreb: August Cesarec/Naprijed.

Malcolm, Janet (1984), In the Freud Archives, New York: Alfred A. Knopf.

Masson, Jeffrey Moussaieff (1984) The Assault on Truth: Freud's Suppression of the Seduction Theory, New York: Farrar, Straus and Giroux.

Molnar, Michael ed. (1992), The Diary of Sigmund Freud 1929-1939. A Record of the Final Decade. Translated, Annotated, with an Introduction by Michael Molnar, London: The Hogarth Press.

Proust, Marcel (1977). Pronađeno vrijeme II. Zagreb: Zora-GZH (prijevod V. Tecilazić).

Rancière, Jacques (2015). Politike vremena, "Vrijeme, pripovijest i politika", sveska br. 6, Beograd: Edicija Jugoslavija (biblioteka sveske).

Rancière, Jacques (2017). Modern Times, Zagreb: Multimedijalni institut.

Shakespeare, William (1950), Hamlet. Zagreb: Nakladni zavod Matice hrvatske (prijevod Milan Bogdanović).

Shakespeare, William (1968), Pericles, Prince of Tyre, New York: Washington Square Press.

Shakespeare, William (1987). Periklo. Zagreb: Nakladni zavod Matice hrvatske (prijevod L. Paljetak).

Shakespeare, William (1994), Hamlet, London: Penguin Books

Žižek, Slavoj (1976). Znak/označitelj/pismo, Beograd: Ideje. 